\title{
MAPEAMENTO DE CAMPOS INSTITUCIONAIS PARA COMBATE À DESINFORMACÃO: PROPOSTAS DE CHECAGEM, DESMONETIZAÇÃO, REGULAÇÃO E EDUCAÇÃO MIDIÁTICA
}

\author{
Ivan Paganotti*
}

\section{RESUMO}

Em cenário de preocupação coletiva com a multiplicação de fake news em diferentes espaços, esta pesquisa questiona como diferentes instituições (de empresas ou organizações não-governamentais, agências de comunicação até candidatos e partidos políticos em campanhas eleitorais) se apropriam de estratégias de verificação de fatos, campanhas educativas de conscientização, pressão por boicote ou combate legal ao que é visto como "notícias falsas". Para isso, é necessário comparar diferentes estratégias de intervenção (correções institucionais, alertas de checadores de fatos, iniciativas de educomunicação, pressão contra anunciantes e propostas legais de controle comunicacional) para municiar o público de habilidades e conhecimentos para evitar a desinformação. Procura-se identificar e classificar diferentes agentes (da comunicação institucional de assessorias de imprensa até o fact-checking de agências de notícias, passando pelo media literacy de iniciativas de educomunicação e interação e respostas de demandas de usuários em redes sociais) que procuram se destacar no debate coletivo com diferentes discursos de autoridade (do direito, do jornalismo, da educação e da comunicação institucional), avaliando também a reação do público de diferentes canais a esses conteúdos. Palavras-chave: checagem, comunicação institucional, desinformação, educomunicação, jornalismo, notícias falsas.

\section{INTRODUCÃO}

Em resposta à preocupação com a disseminação de notícias falsas, instituições distintas apresentam soluções contrastantes a esse desafio. Esta pesquisa procura avaliar os efeitos diretos e indiretos, obstáculos e danos

* Professor da Universidade Metodista de São Paulo (Umesp), desenvolve pesquisa com auxílio da FAPESP - processo no 2020/15055-9, Fundação de Amparo à Pesquisa do Estado de São Paulo (FAPESP). Doutor pela Universidade de São Paulo (USP). ivan.paganotti@metodista.br . 
colaterais de propostas educacionais, jornalísticas, políticas e legais que procuram responder ao atual cenário de desinformação, avaliando a resistência ou o acolhimento dessas propostas por parte mobilizada do público nas redes sociais. Assim, é possível também recomendar para atores públicos e particulares estratégias diferentes para modular suas respostas a situações de crise, preservando sua reputação e apresentando ao público informações e posicionamentos fundamentados e ponderados.

No início do século XX, as primeiras propostas que pretendiam intervir sobre os efeitos dos meios de comunicação no público já consideravam a importância de minimizar seus efeitos negativos, preservando seu potencial pedagógico. A preocupação midiática, ora vista como ameaça moral, ora como oportunidade educativa, une duas pontas que parecem antagônicas nas primeiras reflexões e práticas de educação para as mídias. Citelli (2010) destaca que a histeria sobre os efeitos do incipiente cinema sobre a juventude criou propostas de controle e censura com subterfúgios supostamente educacionais nos EUA; ao mesmo tempo, no Brasil, outro veículo de mídia, o rádio, era visto como suporte para difundir conteúdos educativos massificados ao público. Novas abordagens sobre a educação, como a de Freire e Guimarães (2011), reconhecem papel mais dialógico no processo de aprendizado, distanciando-se das anacrônicas representações desse processo como uma simples correia de transmissão de conteúdos entre um polo ativo e outro passivo - e passam a reconhecer também a importância de inserir na sala de aula a discussão sobre meios de comunicação, que tanto interessam os alunos e contribuem para sua formação paralela. A educação e a comunicação são encaradas como complexo processo de influências mútuas, e seus agentes recebem e produzem mensagens de forma inovadoras, críticas ou inesperadas. Entre os dois campos, Buckingham (2003, p. 4, tradução do autor) defende a importância de uma educação para as mídias para "desenvolver tanto a compreensão crítica quanto a participação ativa”, criando com isso as condições para uma avaliação criteriosa e autônoma sobre o que é consumido ou produzido por meio da mídia.

Ainda assim, persiste a desconfiança midiática, que passou do cinema, da televisão e dos jogos eletrônicos, no século passado, para a interconexão em redes sociais online. Novamente se teme que o público não consiga lidar com a responsabilidade de interpretar criticamente a mídia, mas dessa vez a ameaça se multiplicaria em plataformas como Twitter, Facebook, Whatsapp e Instagram. Esses novos canais parecem atrair ainda mais preocupação 
devido ao seu potencial de viralização, visto que o mesmo público que não conseguiria filtrar os conteúdos considerados inapropriados é também seu propagador, compartilhando mensagens de intolerância, ofensas, incitação à violência e mentiras.

Um fenômeno em particular parece atrair cautela atual: a disseminação de notícias falsas. Ainda que não esteja claro o grau de influência da proliferação das chamadas fake news sobre a formação da opinião pública (ALLCOT'T; GENTZKOW, 2017), cresce o receio de que muitos não saibam descartar fontes de informação que simulam o estilo jornalístico para enganar (TANDOC JR.; LIM; LING, 2017) e acabem contagiando seus contatos ao difundir o conteúdo falso por redes sociais. Ao mesmo tempo, essas plataformas passaram também a ser vistas como um espaço para a difusão de mensagens corretivas e educativas: pelos mesmos canais em que fake news viralizam, pode-se também inocular seus antídotos (PAGANO'TTI, 2018).

A preocupação em relação à ameaça de notícias falsas se tornou um terreno fértil para demandas coletivas por propostas para combater a desinformação. Três caminhos incidem na recepção do público sobre essas notícias: checadores de fatos [fact-checkers] procuram remediar casos de informações falsas disseminadas, corrigindo os erros e alertando que se enganou (HAIGH et al, 2017); educomunicadores procuram prevenir esse cenário de desinformação, apresentando aos usuários habilidades e conhecimentos necessários para identificar fontes de informação de qualidade; e reguladores procuram controlar a circulação dessas informações, erradicando as mensagens e combatendo quem as dissemina com ameaças de punição.

Essa pesquisa pretende avaliar como diferentes entidades oscilam entre esses três polos (verificação/educação/sanção) na definição de sua comunicação institucional ao lidar com informações que são consideradas como incorretas ou são vistas como ameaças à reputação pública - e por isso demandam uma resposta retificadora, didática ou censória. Se a proliferação de canais e fontes desafia a centralidade de instituições tradicionais, que enfrentam mais dificuldade para controlar sua reputação e imagem pública (PAGANOT'TI, 2016), a recente desconfiança em relação às fontes de informação de baixa credibilidade pode ser capturada e usada - de forma bastante problemática - para desacreditar ou silenciar contestações e perspectivas críticas.

Allcott e Gentzkow (2017, p. 213, tradução do autor) conceituam fake news como "artigos noticiosos que são intencionalmente e verificavelmente falsos, e que podem enganar seus leitores". Ao sistematizar dezenas de defi- 
nições diferentes para esse mesmo termo, Tandoc Jr, Lim e Ling (2017, p. 2, tradução do autor) destacam um sentido prevalente de que fake news seriam "publicações virais baseadas em relatos que são feitos para se parecer com reportagens jornalísticas". A definição destaca a fraude, mimetizando características estéticas de publicações jornalísticas online. Já Christofoletti (2018, p. 62) defende que as fake news "viralizam nas redes sociais, espalhadas por indivíduos desavisados ou interessados e por sistemas automatizados, como bots e algoritmos", ou seja, por atores com ou sem intenção de ludibriar. Ribeiro e Ortellado (2018) apontam que ainda há dúvidas sobre a delimitação desse conceito, que pode ou não incluir casos de exageros, especulações, enganos, omissões e informações descontextualizadas, além de episódios em que a intencionalidade da fraude não seja clara.

Como consequência dessa indefinição conceitual, as propostas para combate ao problema podem levar a novas armadilhas, pois práticas muito diferentes podem acabar sendo incluídas na mesma categoria como fake news. Como mencionado anteriormente, em resposta à demanda do público, preocupado com as notícias falsas, medidas diferentes têm sido adotadas, incluindo mudanças no funcionamento de redes sociais e ferramentas de busca online ou novas leis para punir quem cria e compartilha esses conteúdos inverídicos (PAGANOTTI, 2018). Haigh, Haigh e Kozak (2017) defendem que seria mais fértil investir em checagem de fatos - "fact-checking" - e capacitação do público para desmascarar fraudes pela internet. Ribeiro e Ortellado (2018) também apresentam ressalvas às soluções técnicas e as propostas de intervenção legal, que podem apresentar efeitos colaterais negativos, limitando ou punindo críticas online. Lessig (2006) já nos lembrava da utilidade em distinguir os efeitos resultantes em mudanças em códigos legais e nos códigos de programação: enquanto os primeiros demandam deliberação coletiva para que a legitimidade e a eficácia das decisões de um pequeno grupo sejam reconhecidas pela coletividade, conseguindo assim influenciar indiretamente os comportamentos indesejáveis que deveriam ser evitados, os últimos podem apresentar processos muito mais diretos, sofrendo alterações bruscas e inapeláveis, que determinam as ações possiveis dentro de suas plataformas.

Partindo das quatro instâncias para a regulação de condutas - restrições da sociedade, do estado, do mercado e da tecnologia - sistematizadas por Lessig (2006), Ribeiro e Ortellado (2018) classificam e analisam os fundamentos e efeitos do combate às notícias falsas. Os autores apontam as dificuldades provenientes das mudanças nas plataformas digitais, como a 
criação de novos algoritmos para identificar notícias falsas. Ainda assim, nos últimos anos, ferramentas de pesquisa e redes sociais como Google, Facebook e Twitter adotaram mudanças nos seus mecanismos de classificação para reduzir a visibilidade de conteúdos de fontes de credibilidade questionável (PAGANOTTI, 2018). Nesse mesmo sentido é possível incluir mudanças nos termos de conduta, as regras exigidas para os usuários dessas plataformas, restringindo a propagação ou até mesmo removendo conteúdos ou usuários como punição para abusos. Essas propostas procuram exercer influência sobre dois principais mecanismos motivadores para a criação de fake news identificados por Allcott e Gentzkow (2017): recursos financeiros advindos de propaganda online ou influência política.

Ribeiro e Ortellado (2018) também consideram problemáticas as dezenas de propostas de regulação estatal para punir a propagação de conteúdo falso, destacando que novas leis poderiam punir colateralmente os usuários engajados no polarizado debate virtual e que compartilham sem perceber alguns conteúdos falsos que aparentam se encaixar em suas crenças. Em outras nações que cogitam ou já aprovaram leis contra fake news, como na Malásia, essas medidas enfrentam resistência pois podem ser usadas para cercear o debate público, impedindo denúncias ou até mesmo críticas (FUNKE, 2018), o que levou a revisões ou até abandono das propostas originais.

Com o crescimento de sua popularidade, o termo "fake news" passou também a descrever um "jornalismo que não deveria ser levado a sério porque seria falso, manipulado ou indistinguível da ficção" (McNAIR, 2018, p. 6, tradução do autor). Para Ribeiro, Calais e Almeida (2017), críticas embasadas e informações que passaram por verificação e checagem, publicadas por veículos jornalísticos tradicionais com credibilidade também são questionadas ou descartadas se não se encaixem nas preconcepções de parte do público.

O cenário pode parecer intrinsicamente conectado com a realidade atual das redes sociais digitais e as novas tecnologia que permitem produzir vídeos falsos com precisão, os chamados deepfakes (GÜERA; DELP, 2018). Mas é importante destacar que esse fenômeno não é de todo novo. Keyes (2004) lembra que o termo "pós-verdade", que foi popularizado em anos recentes, apresenta uma tradição bem antiga: originalmente, o termo que se refere às "circunstâncias em que os fatos objetivos são menos influentes na formação da opinião pública do que apelos a emoções ou crenças pessoais" havia sido cunhado originalmente pelo dramaturgo sérvio-americano Steve Tesich em artigo na revista The Nation de 1992 sobre os escândalos políticos nos EUA 
nas décadas anteriores (KREITNER, 2016). Entretanto, o termo passa por renascença, sendo visto como uma síntese dos novos tempos em que veículos de mídia tradicional perdem espaço e prestígio na disputa pela atenção de parte considerável do público imerso nas novas mídias e nos novos atores que criam espaços alternativos e cada vez mais influentes.

O objeto dessa pesquisa envolve justamente os impactos da ascensão de fake news sobre instituições que pretendem contestar informações falsas em processos interativos com o público, mas é importante reforçar que não são somente as instituições envolvidas primordialmente nesse embate que são afetadas pelo fenômeno. Agências de checagem jornalística, iniciativas de educomunicação e ameaças de punições formam polos extremos de diferentes estratégias discursivas que servem como baliza para instituições preocupadas com sua visibilidade pública.

Srour (2008, p. 67) defende que a reputação de uma instituição pode ser vista como "reserva de credibilidade" ou "crédito de confiança", que garante "o benefício da dúvida em situação de crise". Esses episódios de crise surgem, por exemplo, quando denúncias e críticas são apresentadas, e a instituição precisa se explicar, corrigir ou até reparar seus erros. Em um cenário de multiplicação de canais e interagentes, mesmo as menores críticas ou denúncias de usuários apresentam um potencial de viralização, atraindo a atenção e causando preocupação entre gestores que ainda enfrentam dificuldade em reconhecer vozes múltiplas que demandam respostas. Quando são alvo de informações falsas que podem afetar negativamente suas reputações, instituições reagem com estratégias que podem envolver desde ignorar acusações inválidas para não auxiliar indiretamente sua propagação até ameaças judiciais contra propagadores, passando por contestações que questionam as fontes de informação ou apresentam dados ou perspectivas alternativas.

Diferentes instituições enfrentam um grande desafio de acompanhar, avaliar e responder a diferentes informações ou posicionamentos online que possam afetar sua reputação. Considerando a preocupação coletiva com o fenômeno crescente da desinformação, instituições podem se aproveitar da desconfiança em relação a fontes de informação com menor credibilidade percebida por diferentes públicos e procurar erodir a credibilidade das fontes de informação, contestar as informações apresentadas ou rebater as opiniões adversas. Assim, essa presente pesquisa parte do seguinte problema: como diferentes instituições (agências de comunicação, empresas, entidades governamentais, organizações do terceiro setor, ativistas, usuários comuns, candidatos e partidos politicos) 
procuram apresentar e fortalecer suas informações e posições no combate às noticias falsas, adotando estratégias de verificação de fatos, educação midiática ou ameaças e punições?

Nesse sentido, este estudo tem como objetivo avaliar como diferentes instituições procuram combater notícias falsas ao se apropriar de estratégias de verificação, conscientização ou punição legal. Para isso, este trabalho compara as reações de diferentes públicos às abordagens jornalísticas, educacionais e legais no combate à desinformação, identificando aplicações possíveis para a comunicação institucional do setor público, privado, de atores sociais ou agentes políticos no enfrentamento de críticas e informações que possam afetar suas reputações.

\section{DESENVOLVIMENTO}

O objeto dessa pesquisa são instituições que procuraram intervir sobre as condutas dos usuários que se envolviam na circulação de notícias falsas em redes sociais a partir dos três eixos identificados anteriormente (verificação/ educação/sanção).

Para isso, é necessário construir um panorama do campo de combate à desinformação, identificando como diferentes instituições se posicionam em relação a esses três eixos. A análise a seguir tomará instituições exemplares que funcionam como representantes de cada uma dessas formas de atuação, mas não devem ser compreendidas como as únicas a atuarem nesses polos: pelo contrário, foram selecionadas para destaque devido ao seu caráter representativo de uma coletividade de instituições semelhantes, com as quais se relacionam, complementam e colaboram. Cada uma das instâncias a seguir é alvo de análise como exemplo de práticas e valores adotados em seus respectivos campos jornalísticos, educacionais e políticos.

A primeira instituição que pode ser destacada é o robô Fátima - https:// fatima.aosfatos.org - desenvolvido pela agência de checagem Aos Fatos para interagir com usuários do Messenger e do Twitter: ela responde a dúvidas e ajuda os usuários a fazer suas próprias checagens, além de identificar usuários que postam links que já foram refutados pelos checadores, apontando o erro. A segunda entidade é o curso online gratuito "Vaqa, Falsiane?" - https://vazafalsiane.com - desenvolvido pelo pesquisador responsável por essa pesquisa, com apoio e financiamento do Facebook. O curso procura apresentar aos usuários conhecimentos e habilidades básicas para compreender a disseminação de dados por redes sociais, avaliando a qualidade de fontes de informação de forma a consumir e compartilhar notícias de forma responsável. A terceira 
instância são as iniciativas de projetos de lei que apontam punições para a criação e a difusão de informações falsas, como é o caso do PL 2630/2020, que trata da Lei Brasileira de Liberdade, Responsabilidade e Transparência na Internet - alcunhado de "Lei das Fake News" - e outras propostas mais antigas, como a PL 9931/2018, que pretende tipificar o crime de divulgação de notícias ou informações falsas e o PL 9533/2018, que define que postagens em redes sociais de incitação sejam classificadas como crimes contra a segurança nacional. Nesse terceiro sentido punitivo, é possível também incluir iniciativas de pressão sobre anunciantes que financiam direta ou indiretamente sites que propagam redes sociais: esse é o caso do perfil Sleeping Giants Brasil - https://twitter.com/slpng_giants_pt - que une usuários em redes sociais dispostos a expor e cobrar anunciantes para que removam propagandas de sites acusados de difundir notícias falsas.

As duas primeiras propostas foram lançadas em 2018, com apoio financeiro do Facebook (2018) - e a segunda iniciativa foi desenvolvido pelo pesquisador responsável por este projeto, em colaboração com pesquisadores, jornalistas e educadores da PUC-SP e da Faculdade Cásper Líbero. Plataformas de redes sociais como o Facebook já demonstraram interesse em intervir sobre o problema das notícias falsas com alterações nos seus algoritmos (PAGANOTTI, 2018), e o apoio ao jornalismo profissional e propostas de educação do público são o próximo passo lógico - mas ainda é importante destacar a eficácia limitada dessas iniciativas que incidem sobre condutas dos usuários em contraste com as alterações sobre os códigos de programação (LESSIG, 2006). O terceiro polo, incluindo os projetos de lei, ainda encontra-se em processo incipiente no Brasil, apesar de tentativas frustradas no final de 2017, durante a reforma política (PAGANOT'TI, 2018) e dezenas de projetos semelhantes em esferas estaduais e municipais; já o perfil no Sleeping Giants no Twitter seria responsável por desmonetizar sites que propagam informações falsas e discurso de ódio, conseguindo que muitos anunciantes removesses suas propagandas dessas plataformas ou impedindo que esses sites pudessem receber doações por plataformas de crowdfunding.

Além do próprio conteúdo produzido pelos emissores dessas iniciativas acima, é importante levar em consideração a reação do público, por meio de postagens em redes sociais abertas, como o Twitter e Facebook, além de respostas institucionais de comunicadores envolvidos nessas polêmicas (como anunciantes, ou responsáveis pela propagação de informações falsas). Essas iniciativas do setor privado, da academia e do setor público podem ser to- 
madas como baliza para estudos futuros que partem dessa triangulação entre os polos jornalístico, educacional e legal para identificar e classificar como outras instituições procuram reagir às informações e desacreditar fontes como ilegítimas, procurando com isso impor suas perspectivas e seu papel como autoridades na definição de verdades com validade e legitimidade. Em panorama sobre diferentes métodos para o estudo do fenômeno das fake news, Jankowski (2018, p. 252) destaca as pesquisas de recepção como uma forma de avaliar a atenção, lembrança, avaliação e crença do público em relação a essas informações, além de outros comportamentos resultantes do contato com esse conteúdo. Nesse sentido, é importante considerar como diferentes segmentos do público interagem com as mensagens produzidas por instituições que promovem a checagem de fatos, a educação midiática ou apresentam propostas legislativa para punir quem cria ou compartilha conteúdos falsos.

\section{CONSIDERACÕES FINAIS}

Este estudo dá continuidade a pesquisa já em andamento nos últimos anos sobre diferentes iniciativas de combate à desinformação (PAGANOTTI, 2018). Além do curso "Vaza, Falsiane!" e do robô Fátima, diferentes ações sociais procuram diminuir os impactos de fake news, para combater as suas causas ou afetar seus mecanismos de propagação. Assim, é importante sistematizar as intervenções adotadas para combater fake news, classificando-as segundo os agentes envolvidos, os objetivos almejados e os métodos empregados, considerando particularmente os efeitos colaterais que venham a incidir sobre outros veículos jornalísticos. Para isso, é importante considerar as transformações nas plataformas de redes sociais, propostas de regulação e estratégias de diferenciação de veículos, considerando particularmente quais as estratégias que cada um desses atores adotará para dar visibilidade sobre seus métodos e objetivos.

Essa cartografia das iniciativas em três polos opostos ou complementares (no jornalismo, na educação e na legislação) é um primeiro passo essencial para posterior panorama de como essas estratégias podem ser mescladas em discursos institucionais de entidades privadas, públicas e atores políticos e sociais que adotam estratégias de verificação, conscientização ou sanção, classificando como "notícias falsas" as informações que podem afetar sua reputação. Entidades que se conectam com o setor da saúde devem ser um foco privilegiado em tempos de pandemia e viralização de conteúdos falsos que desinformam e podem levar parte do público (e seus representantes 
eleitos) a tomar decisões trágicas, baseadas em premissas incorretas. Da mesma forma, também é importante acompanhar estratégias de comunicação institucional adotadas por campanhas políticas de partidos e candidatos à eleição presidencial em 2022, considerando o que esses atores classificam como "notícias falsas" e quais mecanismos de checagem, educação ou sanção são adotados em suas campanhas. Em outras nações, como nos Estados Unidos, a desinformação sobre temáticas eleitorais quanto as informações sem embasamento científico sobre a pandemia de Covid-19, sincronizadas em 2020, levaram plataformas de redes sociais a medidas mais drásticas, removendo conteúdos e contas com acusações sobre fraude eleitoral sem embasamento ou questionando a segurança da vacinação - mesmo perfis de alta visibilidade como o então presidente dos EUA, Donald Trump, perderam suas plataformas em diversas redes sociais (WALLACE, 2021).

Por fim, é possível destacar algumas conclusões, ainda que parciais, desta pesquisa até o momento, indicando uma agenda para estudos futuros. Em primeiro lugar, se o estilo jornalístico padronizado pode ter aberto espaço para imitadores, essa linguagem deve ser justamente o mecanismo adotado para o público diferenciar veículos sérios de fraudes. Nesse sentido, é importante verificar, na avaliação da recepção do público sobre os conteúdos educativos, se os usuários são capazes de identificar essa emulação de recursos de gênero e estilo jornalístico por parte de disseminadores de conteúdos falsos.

Outra questão que necessita de posterior confirmação é sobre os efeitos possíveis das plataformas de checagem jornalística que já atuavam na verificação de informações apresentadas por representantes políticos e por entidades particulares, e passam também a verificar boatos e fake news. Todas procuram verificar informações que circulam na esfera pública para garantir que o debate seja feito com base em pressupostos sólidos, classificando as informações em gradações que vão da mentira completa até a informação sólida e verificável em fontes oficiais, passando por gradações que envolvem exageros, contradições, distorções e dados impossíveis de serem verificados. Essas agências fazem parte do International Fact-Checking Network (IFCN), que soma mais de 70 entidades de checagem em nações de todos os continentes. Como o objetivo desses sites é permitir que o público verifique as informações que circulam nos mais diversos canais, muitos sites de noticiário fraudulento foram expostos por seus veículos ou por outros veículos de comunicação tradicionais. Ainda assim, Sunstein (2010, p. 60) alerta que muitos dos leitores de fake news podem ser "resistentes à correção", visto que 
parte do público pode desconfiar ideologicamente dos meios de comunicação tradicionais (BOYD, 2017) que denunciam as suas mentiras. Pela análise da interação dos usuários com verificadores de fatos seria possível avaliar se os usuários acataram ou resistiram à intervenção da correção dos checadores e se é possível identificar uma mudança no comportamento desses usuários, avaliando as fontes de informação que eles passam a checar depois da interação, em comparação com o que usualmente compartilhavam antes. Dessa forma, seria possível avaliar se a estratégia de checagem e refutação com a demonstração dos métodos e fontes de apuração pode ser replicada de forma eficaz por diferentes entidades. É particularmente importante destacar, nesse sentido, que princípios da checagem de fatos defendido pela IFCN - como a independência e o equilíbrio - pode ser comprometido quando essa checagem é conduzida por um agente interessado nas informações passíveis de contestação - como no caso de um partido político em meio a uma disputa eleitoral, ou uma empresa que se defende de acusações, por exemplo.

Considerando tendência já perceptível atualmente, espera-se no futuro que redes sociais e ferramentas de pesquisa online também apresentem novas intervenções técnicas sobre suas plataformas e algoritmos, de forma a diminuir os incentivos para a propagação de notícias falsas, eventualmente diminuído sua circulação ou até mesmo removendo esse conteúdo completamente. Apesar de capitalizarem com anunciantes sobre clicks dos usuários que interagem com esse conteúdo duvidoso, as empresas responsáveis pelas redes sociais percebem que seu negócio pode estar ameaçado a longo prazo se parte do público passar a descartar seus sites como confiáveis devido à proliferação de notícias fraudulentas. Plataformas de pesquisa como o Google e redes sociais como o Twitter e Facebook (MOSSERI, 2016) já anunciaram mecanismos para alertar seus usuários sobre artigos com informações questionadas por agências de checagem (incluindo a explicação para a dúvida da veracidade dessas informações), permitindo também que o próprio público possa denunciar artigos com informação falsa, diminuindo sua visibilidade nos feed iniciais de outros usuários. A longo prazo, a comparação de resultados acumulados dessas iniciativas jornalísticas, educacionais e político-legais, será possível identificar diferentes indicadores de eficácia para cada abordagem, indo além de índices de influência (como seguidores/compartilhamentos), analisando também eventuais alterações nos comportamentos dos impactados por essas iniciativas. 


\section{REFERÊENCIAS}

ALLCOT'T, Hunt; GENTZKOW, Matthew. Social Media and Fake News in the 2016 Election. Journal of Economic Perspectives, vol. 31, n. 2, p. 211-36, abr-jun, 2017.

BORDEN, Sandra L.; TEW, Chad. The role of journalist and the performance of journalism: ethical lessons from "fake" news (seriously). Journal of Mass Media Ethics, Abingdon, vol. 22, n. 4, dez. 2007.

BOYD, Danah. Did Media Literacy Backfire? Data \& Society: Points, 05/01/2017. Disponível em: https://points.datasociety.net/did-media-literacy-backfire-7418c084d88d.

BUCKINGHAM, David. Media education: literacy, learning and contemporary culture. Cambridge: Polity, 2003.

CHRISTOFOLETTI, Rogério. Padrões de manipulação no jornalismo brasileiro: fake news e a crítica de Perseu Abramo 30 anos depois. Rumores, v. 12, n. 23, jan.-jun, 2018.

CITELLI, Adilson. Comunicação e educação: convergências educomunicativas. Comunicação, Mídia e Consumo, São Paulo, vol. 7, n. 19, p. 67-85, jul. 2010.

FACEBOOK. Facebook apoia projetos no Brasil para combater desinformação. Facebook Newsroom, 4 jan. 2018. Disponível em: https://about.fb.com/br/news/2018/01/facebook-apoia-projetos-no-brasil-para-combater-desinformacao.

FUNKE, Daniel. A guide to anti-misinformation actions around the world. Poynter, Florida, 24 jul. 2018. Disponível em: https://www.poynter.org/ifcn/anti-misinformation-actions.

FREIRE, Paulo; GUIMARÃES, Sérgio. Educar com a mídia: novos diálogos sobre educação. São Paulo: Paz e Terra, 2011.

GÜERA, David; DELP, Edward J. Deepfake Video Detection Using Recurrent Neural Networks. 15th IEEE International Conference on Advanced Video and Signal Based Surveillance (AVSS). Auckland: IEEE, 2018.

HAIGH, M.; HAIGH, T.; KOZAK, N.I. Stopping fake news. Journalism Studies, 2017.

JANKOWSKI, Nicholas W. Researching Fake News: A Selective Examination of Empirical Studies. Javnost - The Public, v. 25, n. 1-2, p. 248-255, 2018.

KEYES, Ralph. The post-truth era: dishonesty and deception in contemporary life. New York: St. Martin's Press, 2004.

KREITNER, Richard. Post-Truth and Its Consequences: What a 25-Year-Old Essay Tells Us About the Current Moment. The Nation, 30 nov. 2016.

LESSIG, Lawrence. Code version 2.0. New York: Basic books, 2006.

McNAIR, Brian. Fake news: falsehood, fabrication and fantasy in journalism. New York: Routledge, 2018.

MOSSERI, Adam. "News Feed FYI: Addressing Hoaxes and Fake News". Facebook Newsroom, 15/12/2017. Disponível em: https://about.fb.com/news/2016/12/news-feed-fyi-addressing-hoaxes-and-fake-news.

PAGANOTTI, Ivan. A negação da negativa em um palimpsesto de propaganda: conflitos entre liberdades em expressões sobre a campanha de Carnaval da cerveja Skol em 2015. Revista Observatório, Palmas, v. 2, n. 1, p. 318-339, jan.-abr. 2016.

PAGANOTTI, Ivan. "Notícias falsas", problemas reais: propostas de intervenção contra noticiários fraudulentos. In: COSTA, Maria Cristina Castilho; BLANCO, Patrícia (Orgs.). Pós-tudo e crise da democracia. São Paulo: ECA-USP, 2018, p. 96-105. 
PAGANOTTI, Ivan; SAKAMOTO, Leonardo; RATIER, Rodrigo. Entre a legalidade e a legitimidade: divergências e fundamentações na definição e bloqueio de 'notícias falsas' pelo TSE. Brazilian Journalism Research, v. 16, n. 2, p. 330-353, 2020.

RIBEIRO, Manoel Horta; CALAIS, Pedro H.; ALMEIDA, Virgílio A. F.; MEIRA JR, Wagner. “Everything I Disagree With is \#Fake News': Correlating Political Polarization and Spread of Misinformation". DS+J, Cornell, ago. 2017.

RIBEIRO, Márcio Moretto; ORTELLADO, Pablo. O que são e como lidar com as notícias falsas. SUR - Revista Internacional de Direitos Humanos, São Paulo, n. 27, jul. 2018.

ROSS, Andrew S.; RIVERS, Damian J. Discursive Deflection: Accusation of "Fake News" and the Spread of Mis- and Disinformation in the Tweets of President Trump. Social Media + Society, v. 4, n. 2, abr.-jun. 2018.

SROUR, Robert Henry. Por que empresas eticamente orientadas? Organicom, São Paulo, vol. 5, n. 8, p. $59-67,1^{\circ}$ semestre de 2008 .

SUNSTEIN, Cass. A verdade sobre os boatos: como se espalham e por que acreditamos neles. Rio de Janeiro: Elsevier, 2010.

TANDOC JR., Edson C.; LIM, Zheng Wei; LING, Richard. Defining 'Fake News' - A typology of scholarly definitions. Digital Journalism, vol. 6, n. 2, p. 137-153, ago. 2017.

WALLACE, Arturo. Como as redes sociais bloquearam Trump e por que isso gerou um grande debate sobre liberdade de expressão. BBC, 14 jan. 2021. Disponível em: https://www.bbc.com/portuguese/ internacional-55664816. 